\title{
A Study of Power Management Techniques in Green Computing
}

\author{
Sadia Anayat
}

Govt. College Woman University Sialkot

Received: 06 April 2020; Accepted: 13 May 2020; Published: 08 June 2020

\begin{abstract}
Cloud computing is a mechanism for allowing effective, easy and on-demand network access to a shared pool of computer resources. Instead of storing data on PCs and upgrading softwares to match your requirements, the internet services are used to save data or use its apps remotely. It perform the function of processing and storing a database to provide consumers with versatility. For specialized computational needs, the supercomputers are used in cloud computing. Because of execution of such high performances computers, a great deal of power devoured and the result is that certain dangerous gases are often emitted in a comparable amounts of energy. Green computing is the philosophy that aim to restrict this technique by introducing latest models that would work effectively while devouring less resources and having less people. The basic goal of this study is to discuss the techniques of green computing for achieving low power consumption. We analyze multiple power management techniques used in the virtual enviroment and further green computing uses are mentioned. The advantages of green computing discussed in this study have shown that it help in cutting cost of companies, save enviroment and maintain its sustainability. This work suggested that researchers are becoming ever more invloved in green computing technology.
\end{abstract}

Index Terms: Cloud computing, Green computing techniques, Data center, virtualization , power management, recycling.

(C) 2020 Published by MECS Publisher. Selection and/or peer review under responsibility of the Research Association of Mode rn Education and Computer Science

\footnotetext{
* Corresponding author.

E-mail address:
} 


\section{Introduction}

Cloud computing is evolving as a modern large scale dispersed computing model[1,3]. It has shifted the data and computing into large data centers from PCs and desktop. As computing capacity is increasing rapidly so we have the idea of cloud computing to fulfill this requirement. The cloud computing has the potential to leverage the power of internet and WAN to use the remotely accessible services, thereby offering cost-effective solution to most real life needs. It offer the flexible IT tools on pay-per-use basis. This technology refer to the availability of computing services over the network[2]. With increasing the power utilization, climate change and e-waste, government entities and private businesses take the green compuitng concept seriouly into account as a commitment to good practice for tenable evolution. CC perform the function of processing and storing a database to provide consumers with versatility[3]. Cloud computing consist of several models. first one is Servive model and second is Deployement model.

Table 1. Cloud computing models

\begin{tabular}{|l|l|l|}
\hline CC Models & Sub-models & Discription \\
\hline Service models & Software as a Servic & the applications, offer by third party over the internet, are ready to use \\
\cline { 2 - 3 } & Platform as a service & $\begin{array}{l}\text { Platform is provided to the user to develope, run and manage application } \\
\text { without maintaining the infrastructure related to development of the } \\
\text { application }\end{array}$ \\
\cline { 2 - 3 } $\begin{array}{l}\text { Deployement } \\
\text { model }\end{array}$ & Infrastructure as a service & Offer externalized computer resource to manage bussiness operations. \\
\cline { 2 - 3 } & private cloud & $\begin{array}{l}\text { User don't need to manage public cloud hosting services. The service } \\
\text { provider maintain the resources }\end{array}$ \\
\cline { 2 - 3 } & Community cloud & $\begin{array}{l}\text { Maintinance, updation and management of data is the responsibility of } \\
\text { user }\end{array}$ \\
\cline { 2 - 2 } & $\begin{array}{l}\text { The network is shared among organisations from single community having } \\
\text { same concerns. It can be controled by user or by third parties and organized } \\
\text { innerly or outerly. }\end{array}$ \\
\cline { 2 - 2 } & Refer to mix computing of private and public cloud. \\
\hline
\end{tabular}

The above tables shows the models of cloud computing. Cloud computing consist of several models. first one is Servive model and second is Deployement model. Cloud models come in three types: SaaS (Software as a Service), IaaS (Infrastructure as a Service) and PaaS (Platform as a Service). There are four cloud deployment models: public, private, community, and hybrid. Each of the cloud models has their own set of benefits that could serve the needs of various businesses. The table 1 provide a brief description of each model.

The key goal of cloud computing is to optimize the pooled resources. Meanwhile its high network cost and excessive power utilization are the downsides. With the ever growing prevalance and use of CC, high energy is used and dengerous gasses are emmited. Thousands of data centers are used in cloud to fulfill the quiries of customors, and large ammount of energy is require for keeping cold and other operations to operate these data centers. The demand of power is increases with the time and Green computing help a lot is curbing these priblems.

The area of green computing cover the wide variety of subjects from modern method of power production to studying the latest technologies to be used in daily lives[4]. It seeks to reduce the sorrounding effects of industrial processes and latest developements brought about by increasing population of planet. It provide an enviromentally friendly method of lessing power and e-waste in the world[2]. The idea of green computing is the effective usage of system resources and information technology infrastructure[5]. The green computing's key objectives are to reduce the usage of harmful and dengerous chemical, and enhance the power efficiency and planet waste recycling. This activity require effective server, outermost deployement and reducing the 
power utilization. The main purpose of this study is to study the power managemnet technqiues of Green Computing. The approaches of Green comuting are discussed in this paper. We analyze multiple power management techniques used in the virtual enviroment and further green computing uses are mentioned. The advantages of green computing discussed in this study have shown that it help in cutting cost of companies, save enviroment and maintain its sustainability. This work suggested that researchers are becoming ever more invloved in green computing technology.

This study is structured as follow: the approaches of green computing are mentioned in section 2 . Then power management techniques are discussed in section 3 and related work is presented in section 4 . Furthermore, advantages/usage of green computing are mentioned in section 5 and discussion is held in section 6 . Then, the conclusion is drawn in section 7 at last.

\section{Approaches of Green Computing}

Different methods are used for achieving Green computing. Some are as follow.

1) Product logevity: Gartner beleives that method of system production account 70 persent of natural resources used in the PC's lifecycle. The main benefaction to green computing, therefore, is typically to extend the lifespan of equipement. Gartner research advices that "seeking the durability of product" including madularity and upgradability. For example, production of new PC allowsan ecological footprint much greater than producing a new random access memory module to update an existing one.

2) Telecommunication network devices energy indices: while when match to other sectors, power uage of information and communication technologies is much imporatnt. Some latest research has worked to recognize the main power indicators that allow compare two different divices. The resaerch centered on how the system and network use can be configured for telecommunication by itself. The goals was to allow an instant understanding of network technology's relationships with the enviromental effects.

3) Software and deployement optimization: it involves arithmatic performance, allotment of resources, final server and virtualisations. The ability of algorithm affect the number of machine tools needed for any specific computing purpose and a lot of efficiency trading opportunities are there in writing programs. Allocation of resources can be saved on power basis. Through virtualization, a system manager may integrate multiple hardware systems on one solid divice in a virtual machine, thus unplugging the initial hardware and minimizing the energy utilization and cooling. Vitualisation can help spread research so that servers are either occupied or in a state of low power sleep. While using the green computer client server, the when client connect to central server, all internal computation is completed on the server but users encounters the terminal operating system(OS). This may be paired with thin consumers, who use upto 1/8 typical workstation's ammount of energy, resulting in energy cost and usage decreasing.

4) Telecommuting: Through green computing projects, the teleconferencing and telepresence techniques are introduced. There are a lot of benefits such as improved staff productivity, reduced travel related green house gass releases and higher profit margin arising from lesser operating cost for office space, electricity, etc.

5) Material recycling: Recycling computing equipement can holf damaging materials such as lead and mercury, which can also change the appratus that would otherwise have to be generated saving extra power and pollution.

6) Data center design: the facilities of data centers are strong energy users. It is reported by U.S energy deparment that data center provisions use up to one hundred to twi hundred times more electricity than normal office buildings. It is also reported that IT systems, air control, ventilation systems and electrical systems are key area of focusing on the best practice in the construction of energy efficient data center.

7) Power management: ACPi enable direct control of power saving aspects of underlying hardwares by operating system. It hel[p the devices to turn off automatically. Additionally, when most components are powered off, the system can sleep. 
8) Super computer: Today, the world most power efficient supercomputer called L-CSC, has emerged as a modern super computer. This marks for the first time that a supercomputer has occupied top spot using AMD GPUs. Every server has 256 gigabytes of memory in it. The server is link through an infiniband FDR network.

All these appraoches are basically used for achieving Green computing. The above discussion shows that The design of energy efficiency data centers would enhance the use of data centers space and enhance the performance. Moreover, The main benefaction to green computing is typically to extend the lifespan of equipement. When components are piwered off, then the system is sleep automatically to save the power. One of the appraoch of Green Computing is Recycling which help to recyle the computer component to save the power and reduce the pollution. Travel related green house gass releases can be reduced and higher profit margin arise from lesser operating cost for office space through green computing pojects. Server Computer is also an approach of Green Computing Which has 256 Gigabytes memory in it.

\section{Green computing techniques to manage power in computing system}

Those techniuqes can be graded at multiple levels.

- Hardware and firmware level

- Operating system level

- Virtualization level

Data center level

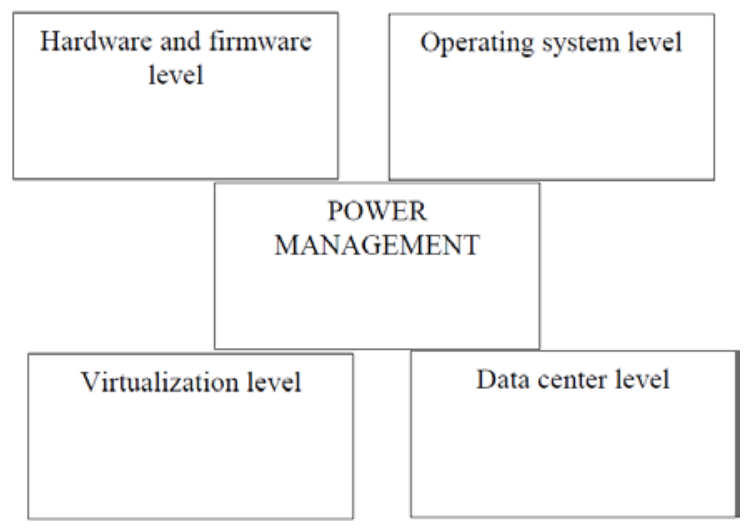

Figure 1. Power management techniques

\subsection{Hardware and firmware techniques:}

These echnologies are implemented during a machine's manufacturing period. These methof includes all the ways of optimization which are implemented at level of logic, circuit, architecture and device when signing. The hardware and fimrware level techniques are split up into two types.

i. Dynamic Component Deactivation(DCD)

ii. Dynamic Performance Scaling(DPS) 


\subsubsection{Dynamic Component Deactivation(DCD)}

The machine part which don't scale the output and can only be turned off idle. In the case of marginal transition, the issue is minor onlyif the free time is the transitions leading not only to late that can effect the output device but also to extra energy. Thus, a switch has to split down into the Predictive and Stochastic.

Predictive techniques are focussed opon the coorelation among device behaviour previous experience and its forseeable future. A inadequate prediction can over or under. In under prediction, the real free time is smaller than one expected leading predicted that would result in sanction of success. The predictive technique can further divided into static and adaptive. Static techniques use a few electronic to estimate the idle period for an actual time processing parameter. Adaptation is to hold a list of interested paramet values and at last pause, allot the weighs to values according to their performance.

In stochastic optimization, a suitable probablistic system model is needed to be construct. The result of stochastic method are predicted values and it is not assured that solution for a given query is best.

\subsubsection{Dynamic Performance Scaling(DPS)}

The DPS provide many technoqiues that are implemented to the system component which enable active performance accomodation propotionally to power utilization. This concept lies in the origins of Dynamic Voltage and Frequency Scaling techniques which is mostly used.

Dynamic Voltage and Frequency Scaling:

In a specific time, the DVFS decrease the statements proceed by processor. Thus the run time for enough CPU-bounded program segmentation is increases.

\subsection{Virtualization level}

The idea of virtual machine is used in these techniques to manage the power. The numbe rof virtual machines are generated on a hardware server, thus to reducing amount of hardware being used and increasing resource consumption. This level allow the separation from the hardware of an operating system and program that run on it. As the virtualization layer is among the physical and operating system, so a VM moniter keep check on the collectivity of resources and must be active in power control of networkfor ensuring effective operations. The VMM is engaged in power management in two ways:

1. The VMM can operate as a energy aware OSwithout discriminating between VMs: track the output of overall system and implement DVS or any DCD method to device component.

2. The second way is exploit the unique power managemnet strategies and expertise at application level of OS and chart power management calls from multiple virtual machines regarding real modifications in the energy level of hardware or harmonize the implementation of systemwide power limitation.

\subsection{Data Center level}

The basic purpose of this level is:

i. Reduce the power utilization, meet efficiency demands.

ii. Reduce energy utilization, recue loss of efficiency.

\subsection{Operating System Level}


The different feature use to define level of OS. These techniques include methods which take care of operating level program.

Table 2. Characteristics of OS level

\begin{tabular}{|l|l|l|l|l|}
\hline Project name & System resources & Power Saving Techniques & $\begin{array}{l}\text { Target } \\
\text { system }\end{array}$ & Goals \\
\hline Ondem and Government & Central processing unit & DVFS & Arbitrary & $\begin{array}{l}\text { Less enery } \\
\text { utilization }\end{array}$ \\
\hline Eco system & $\begin{array}{l}\text { Central processing unit, dis } \\
\text { storage, memory, network } \\
\text { interface }\end{array}$ & Resource threttoling & $\begin{array}{l}\text { Mobile } \\
\text { system }\end{array}$ & $\begin{array}{l}\text { Obtaining } \\
\text { bettery life on } \\
\text { goal }\end{array}$ \\
\hline $\begin{array}{l}\text { Nemisis OS, Neugeba } \\
\text { and Mcauley }\end{array}$ & $\begin{array}{l}\text { Central processing unit, dis } \\
\text { storage, memory, network } \\
\text { interface }\end{array}$ & Resource threttoling & $\begin{array}{l}\text { Mobile } \\
\text { system }\end{array}$ & $\begin{array}{l}\text { Obtaining } \\
\text { bettery life on } \\
\text { goal }\end{array}$ \\
\hline
\end{tabular}

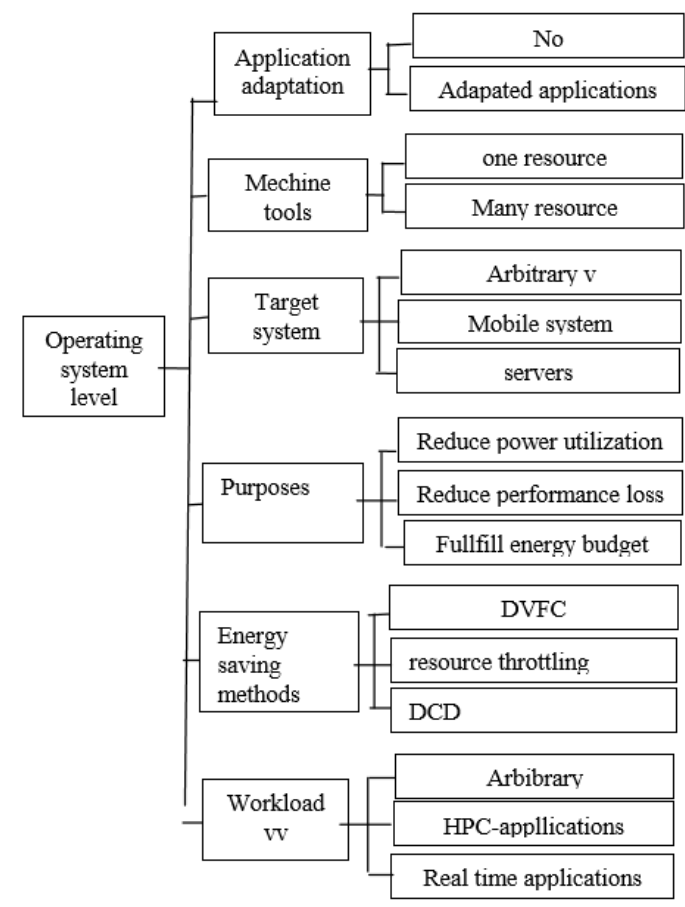

Figure 2. OS level

\section{Related work}

A centralized observing body was suggested by George Perreas[6] which try to decrease the power utilization in Internet Data centers using live VMs migration between blade servers using statistics obtained by servers are analyzed to conduct live relocation of virtual machine and the server that can be unload are picked. Virtual machines belonging to servers that could be downloaded will be distributed to other live servers, serving the performance percieved by user is preserved. Feifei chen et al introduced a power utilization model related analytical method for cloud computing[7]. Energy usage based on various runtime activities in CC was measured. Actual study of link between energy utilization and cloud data, and computational task and device efficiency will be studied on the basis of model ans study method for energy 
consumption. A method was presented by Liange-The Lee et al voltage of device charged free or light was minimized and massive loaded jobs were loaded to lighter loading equipment. The resources were managed dynamically with power saving method[8]. EPOBF's FindHostForVM was introduced by Nguyen Quang Hung that is unique from all existing study because EPOBF;s FindHostForVM select with higher ratio of total cumulative MIPS to avarage energy utilization value of host[9]. An algorithm was presented for reduction of power consumption by ChiaTien Dan Lo et al[10]. Fine grained Green computing and Green computing coarse Grained were discussed in this study. Coarse graind computing refer to processing a program in maximum power mode regardless that wether the system uses memory bank or I/O peripherals. Fine-grained Green computing is run a code effectively and successfully through a fine energy control on each computing equipment. Power aware control of resources is important for anHPC data center. Takauna et all presented a model[11] for multicore load scheduling and FindHostForVm to pick the host with less energy utilization increase to allocate a VM. A method was presented for selecting the optimum operating frequancy for a host and setting nmber of virtual core for a VM[12].

Table 3. Analysis of Power management techniques in virtual enviroment

\begin{tabular}{|c|c|c|c|c|c|}
\hline Serial No. & Title & Technique used & Goal & Advantages & Cons \\
\hline 1 & $\begin{array}{l}\text { Efficient resource } \\
\text { management for } \\
\text { cloud compputing } \\
\text { enviroment }\end{array}$ & $\begin{array}{l}\text { Energy based VM } \\
\text { scheduling } \\
\text { algorithm for VM } \\
\text { programming }\end{array}$ & $\begin{array}{l}\text { Improving system } \\
\text { output at data center } \\
\text { with low overhead } \\
\text { cost }\end{array}$ & $\begin{array}{l}\text { Using power based } \\
\text { scheduling, the power } \\
\text { utilization is reduced }\end{array}$ & $\begin{array}{l}\text { Only energy is } \\
\text { considered as Quality } \\
\text { of Service parameter }\end{array}$ \\
\hline 2 & $\begin{array}{l}\text { Minimize the cost } \\
\text { of energy and } \\
\text { network for } \\
\text { internet service } \\
\text { provider } \\
\text { geographically } \\
\text { located network } \\
\text { data centers. }\end{array}$ & $\begin{array}{l}\text { Adaptive } \\
\text { optimization } \\
\text { algorithm. }\end{array}$ & $\begin{array}{l}\text { An optimization } \\
\text { load } \\
\text { dispatching method } \\
\text { to } \\
\text { reduce the total } \\
\text { cost for OSPs. }\end{array}$ & $\begin{array}{l}\text { As compare to previous } \\
\text { study, this take overall } \\
\text { network cost and measure } \\
\text { total cost using carbon } \\
\text { emmision }\end{array}$ & $\begin{array}{l}\text { Consider low number } \\
\text { of quality of service } \\
\text { parameter }\end{array}$ \\
\hline 3 & $\begin{array}{l}\text { Energy based } \\
\text { Efficient Resource } \\
\text { Scheduling: A } \\
\text { Step Towards } \\
\text { Green Computing. }\end{array}$ & \begin{tabular}{lr}
$\begin{array}{l}\text { Energy } \\
\text { efficient }\end{array}$ & $\begin{array}{r}\text { based } \\
\text { tool }\end{array}$ \\
scheduling & \\
algorithm. & Better \\
resource & \\
utilization & \\
techniques & \\
Scheduling & \\
algorithm taking \\
into account \\
\multicolumn{2}{c}{ services efficiency } \\
outlooks. & \\
\end{tabular} & $\begin{array}{l}\text { Architectural rules } \\
\text { for cloud power } \\
\text { management }\end{array}$ & $\begin{array}{l}\text { Better performance in low, } \\
\text { high and random resource } \\
\text { consumption }\end{array}$ & $\begin{array}{l}\text { Take energy only as } \\
\text { QoS parameter }\end{array}$ \\
\hline 4 & $\begin{array}{l}\text { Energy Efficient } \\
\text { Allocation of } \\
\text { Virtual Machines } \\
\text { in } \\
\text { High Performance } \\
\text { Computing Cloud. }\end{array}$ & EPOBF algorithm & $\begin{array}{l}\text { Minimizing phisical } \\
\text { machines overall power } \\
\text { utilization in high } \\
\text { performance cloud and } \\
\text { satisfying quality of } \\
\text { service. }\end{array}$ & $\begin{array}{l}\text { Heterogeneous } \\
\text { Physical machines is } \\
\text { used } \\
\text { and saved more } \\
\text { energy }\end{array}$ & $\begin{array}{l}\text { Only } 35 \text { persent } \\
\text { power is saved }\end{array}$ \\
\hline
\end{tabular}




\section{Usage of Green Computing}

- Reducing the power consumption from renewable computing, converted into low ejection of carbon dioxide from a decrease of fosil fuels which are used in power stations and for transport[2].

- Resource conservation mean lesser power is needed for production, use and disposal of goods.

- Reduce the dangers that occur in PCs such as chemicals substances believed to cause cancer, nerve disorder and human immue reaction.

- $\quad$ Reduce the power usage of systems in enviromentally friendly way.

- Manufacturing the processes of computers with lesser to no enviromental effects.

- Green computing means modifying government policies to allow the people and companies to recucle and reduce their energy consumption.

- Primary goal of green computing are rising energy efficiency and decreasing the use of hazardous material.

- Making information technology "Green” help us to save money and save our enviroment by minimizing and removing wastefull activities[13].

\section{Discussion}

Cloud computing is a mechanism for allowing effective, easy and on-demand network access to a shared pool of computer resources. Because of execution of servers in cloud computing for specialized computation, a great deal of power devoured and the result is that certain dengerous gases are often emitted in a comparable amounts of energy. Green computing provide an enviromentally friendly method of lessing power utilization and e-waste in the world[2]. The area of green computing cover the wide variety of subjects from modern method of power production to studying the latest technologies to be used in daily lives. This technology help to reduce the dangers that occur in PCs such as chemicals substances believed to cause cancer, nerve disorder and human immue reaction. It make information technology "Green" and help us to save money and save our enviroment by minimizing and removing wastefull activities[13]. It enhance the energy efficiency and reduce the power consumption by using multiple techniques.

This research is conducted to discuss the all those techniques used in green coputing for reducing energy consumtion. ffectively while devouring less resources and having less people. The techniques of green computing for achieving low power consumption are discussed in this paper. We analyze multiple power management techniques used in the virtual enviroment and further green computing uses are mentioned. The advantages of green computing discussed in this study have shown that it help in cutting cost of companies, save enviroment and maintain its sustainability. Primary goal of green computing are rising energy efficiency and decreasing the use of hazardous material. Making information technology "Green” help us to save money and save our enviroment by minimizing and removing wastefull activities. The approaches of this technology and an analyses of power management techniques which are used in virtual enviroment is presented in this paper. This study show that renewable computing help us to reduce the E-waste and emmision of dangerous gasses from the system while running. As Green computing means modifying government policies to allow the people and companies to recucle and reduce their energy consumption so the Green computing help to reduce the emission of dangerous gasses from the computing components.

\section{Conclusion}

In this paper, the techniques of green computing for achieving low power consumption are discussed. Various methods used by data centers to achieve energy quality through virtualisation are analyzed and multiple green computing approaches are presented in this study. An analysis of power management techniques in virtualization enviroment has been conducted. The advantages of green computing discussed in 
this study have shown that it help in cutting cost of companies, save enviroment and maintain its sustainability. This research shows that use of Green computing help to reduce the power consumption, save money and decrease the wastage of goods. The study has been showed that Green computing is modifying government policies to allow the people and companies to recucle and reduce their energy consumption so the Green computing help to reduce the emission of dangerous gasses from the computing components. This work suggested that researchers are becoming ever more invloved in green computing technology.

\section{References}

[1] Kansal, Nidhi Jain, and Inderveer Chana. "Cloud load balancing techniques: A step towards green computing." IJCSI International Journal of Computer Science Issues 9.1 (2012): 238-246.

[2] Choudhary, Sonu. "A survey on green computing techniques." International Journal on Computer Science and Information Technology 5.5 (2014): 6248-6252.

[3] Raghava, N. S., and Deepti Singh. "Comparative study on load balancing techniques in cloud computing." Open journal of mobile computing and cloud computing 1.1 (2014): 18-25.

[4] Lakshmi, S. V. S. S., I. S. L. Sarwani, and M. Nalini Tuveera. "A study on green computing: the future computing and eco-friendly technology." International Journal of Engineering Research and Applications (IJERA) 2 (2012): 1282-1285.

[5] Pazowski, Piotr. "Green computing: latest practices and technologies for ICT sustainability." Managing Intellectual Capital and Innovation for Sustainable and Inclusive Society, Joint International Conference, Bari, Italy. 2015.

[6] "Efficient Resource Management for Cloud Computing Environments”, Andrew J.Younge, Gregor von Laszewski, Lizhe Wang,Sonia Lopez-Alarcon, Warren Carithers.

[7] Singh, Sukhpal, and Inderveer Chana. "Energy based efficient resource scheduling: a step towards green computing." Int J Energy Inf Commun 5.2 (2014): 35-52.

[8] Takouna, Ibrahim, Wesam Dawoud, and Christoph Meinel. "Energy efficient scheduling of HPC-jobs on virtualize clusters using host and VM dynamic configuration." ACM SIGOPS Operating Systems Review 46.2 (2012): 19-27

[9] Lo, Chia-Tien Dan, and Kai Qian. "Green computing methodology for next generation computing scientists." 2010 IEEE 34th Annual Computer Software and Applications Conference. IEEE, 2010.

[10] Perreas, George, and Petros Lampsas. "A Centralized Architecture for Energy-Efficient Job Management in Data Centers." CLOUD COMPUTING (2014).

[11] Beloglazov, Anton, and Rajkumar Buyya. "Optimal online deterministic algorithms and adaptive heuristics for energy and performance efficient dynamic consolidation of virtual machines in cloud data centers." Concurrency and Computation: Practice and Experience 24.13 (2012): 1397-1420.

[12] Quang-Hung, Nguyen, Nam Thoai, and Nguyen Thanh Son. "EPOBF: energy efficient allocation of virtual machines in high performance computing cloud." Transactions on Large-Scale Data-and Knowledge-Centered Systems XVI. Springer, Berlin, Heidelberg, 2014. 71-86.

[13] Appasami, G., and K. Suresh Joseph. "Optimization of operating systems towards green computing." International Journal of Combinatorial Optimization Problems and Informatics 2.3 (2011): 39-51.

[14] Polkowski, Zdzisław, Julian Vasilev, and Rashmin Ghandi. "ICT GREEN ECOSYSTEM." Studies \& Proceedings of Polish Association for Knowledge Management 82 (2016): 61-73.

[15] Anwar, Sidra, et al. "E-waste reduction via virtualization in green computing." American Scientific Research Journal for Engineering, Technology, and Sciences (ASRJETS) 41.1 (2018): 1-11. 


\section{Author's Profile}

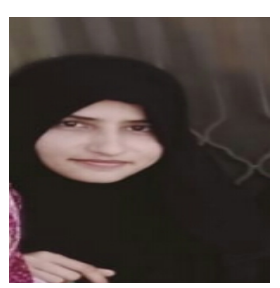

Sadia Anayat did her matriculation level in 2014 from, Govt. Girls Higher Secondary school Sambrial, district Sialkot in Science Subjects and her intermediate level (I.C.S) in 2016 from Superior college Sambrial, district Sialkot. Now she is doing her BS (Hons) in Computer Science (CS) from GCWU Sialkot. She is also certified as Microsoft Office specialist. Currently she is working on research in Blochain technology and comparison between bitcoin and ethereum topic. Her main areas of research interest are blockchian technology, artificial intelligence, image processing, internet of things and wireless sensor network.

How to cite this paper: Sadia Anayat. " A Study of Power Management Techniques in Green Computing ", International Journal of Education and Management Engineering(IJEME), Vol.10, No.3, pp.42-51, 2020.DOI: 10.5815/ijeme.2020.03.05 